\title{
Maternal Age-Associated Congenital Anomalies Among Newborns: A Retrospective Study in Latvia
}

\author{
Irisa Zīle ${ }^{1,2}$, Anita Villeruša ${ }^{1}$ \\ ${ }^{1}$ Department of Public Health and Epidemiology, Riga Stradins University, Latvia, \\ ${ }^{2}$ Centre for Disease Prevention and Control, Department of Research and Statistics, Latvia
}

Key Words: congenital anomalies; newborns; maternal age; prevalence rate.

Summary. Background and Objective. In Latvia, the mean age of women giving birth increased from 27.3 in 2000 to 29.0 years in 2010 during the last 11 years. The aim of this study was to report on major congenital anomalies of newborns at birth by the maternal age and to compare the mean maternal age by different diagnosis subgroups and maternal and neonatal characteristics.

Material and Methods. A cross-sectional retrospective study with the data from the Medical Birth Register (2000-2010) was carried out. The live birth prevalence rate was calculated for the subgroups of major congenital anomalies per 10000 live births by the maternal age.

Results. The live birth prevalence rate of major congenital anomalies during the period 20002010 was 211.4 per 10000 live births. The prevalence rate increased depending on the maternal age. Congenital heart defects, limb defects, and urinary system anomalies were the most common anomalies. The study results showed an age-related risk of abdominal wall defects, orofacial clefts, and chromosomal anomalies. There were significantly higher proportions of preterm births, newborns with low birth weight, and complications during pregnancy among mothers aged 35 years and more.

Conclusions. The data on congenital anomalies from the Latvian Medical Birth Register can be used for the assessment of epidemiology of congenital anomalies. The results of this retrospective study showed a decrease in the live birth prevalence rate of major congenital anomalies despite an increase in the mean age of mothers in Latvia.

\section{Introduction}

A birth defect is typically defined as any abnormality affecting the structure or function of the body that is present from birth (1-3). At least 7.9 million people worldwide are born with a birth defect each year. An average of 3.3 million children under 5 years of age die from birth defects each year, while an estimated 3.2 million of those who survive may have lifelong disability (1). In Latvia, an average of $25 \%-30 \%$ of all infant deaths are caused by congenital malformations (4). The perinatal, neonatal, and infant mortality rates in Latvia are quite high when compared with other European countries and are approximately 2 times higher than the average rate for the European Union (5). In Latvia, the mean age of women giving birth and of primiparas increased from 27.3 to 29.0 years and from 24.4 to 26.4 years, respectively, over the last 11 years (2000 vs. 2010) (6). The statistical data also show a slight increase in the proportion of live births in women aged 35 and more (from $12.9 \%$ in 2008 to $14.8 \%$ in 2010) (4). Simultaneously, the overall prevalence of congenital anomalies at birth in Latvia decreased. Scientific literature has described the effect of the maternal age on the outcome of pregnancy as well as its relationship with newborn's birth defects.

Correspondence to I. Zîle, Department of Public Health and Epidemiology, Riga Stradins University, Kronvalda Blvd. 9, 1010 Riga, Latvia. E-mail: irisa.zile@inbox.lv
Some birth defects such as chromosomal abnormalities (the most common being Down syndrome) or nonchromosomal abnormalities, such as cardiac defects, diaphragmatic hernia, hypospadias, and clubfoot, increase in prevalence with an increasing age of mothers, while other defects have a higher prevalence among younger mothers, including nonchromosomal abnormalities, such as abdominal wall defects (omphalocele and gastroschisis), polydactyly, anencephaly, and hydrocephaly (7-15). The aim of this study was to report on major congenital anomalies of newborns at birth by the maternal age and to compare the mean maternal age by different diagnosis subgroups and maternal and neonatal characteristics. The main research issues were related to the live birth prevalence of major congenital anomalies by the maternal age and to the age-related risk for anomaly subgroups.

\section{Material and Methods}

A descriptive, cross-sectional, retrospective study was carried out using the data from the Medical Birth Register (MBR). The MBR is based on the information provided by cards issued for newborns by maternity units across the country. Of the 233601 total live births in Latvia between 2000 and 2010, there were 7451 live newborns registered with congenital anomalies (International Classification of Disease [ICD-10]; Q00-Q99) at birth. The 
congenital anomalies included in the analyses were diagnosed by a neonatologist using ultrasound examinations and genetic testing. These investigations were performed during the time spent in a maternity unit after delivery.

The data analyzed include the following congenital anomaly subgroups: nervous (Q00, Q01, Q02, Q03, Q04, Q05, Q06, Q07); eye (Q10.0, Q10.4, Q10.6-Q10.7, Q11-Q15); ear, face, and neck (Q16, Q17.8, Q18.3, Q18.8); congenital heart defects (Q20-Q26); respiratory (Q30-Q34); orofacial clefts (Q35-Q37); digestive system (Q38-Q39, Q40.2-Q40.9, Q41-Q45, Q79.0); abdominal wall defects (Q79.2, Q79.3, Q79.5); urinary (Q60-Q64, Q79.4); genital (Q50-Q52, Q54-56); limb (Q65.0Q65.2, Q65.8-Q65.9, Q66.0, Q68.1-Q68.2, Q68.8, Q69-Q74); musculoskeletal system (Q75.0-75.1, Q75.4-Q75.9, Q76.1-Q76.4, Q76.6-Q76.9, Q77, Q78, Q79.6-Q79.9); and other anomalies/syndromes (Q27, Q28, Q80-Q85, Q89) and chromosomal anomalies (Q90-Q92, Q93, Q96-Q99). This classification of the subgroups is based on the $\mathrm{Eu}-$ ropean Surveillance of Congenital Anomalies (EUROCAT) methodology (16).

To describe the study population, we analyzed the different characteristics of mothers and newborns by the maternal age groups. Mothers were categorized by age into 3 groups: $\leqslant 19$ years, 20 to 34 years, and $35 \geqslant$ years. The marital status was also considered in the analysis. Other variables analyzed included the data about antenatal care (if the mother had antenatal care or did not register for and did not receive antenatal care), parity (either primipara or multipara), mother's diseases and complications during delivery and pregnancy, and a history of abortions due to medical reasons. For newborns, birth weight and gestational week were recorded and classified as either low ( $\leqslant 2499$ g) or normal $(\geqslant 2500 \mathrm{~g})$ and preterm birth (22-36 weeks) or term birth (37-42 weeks), respectively.

The live birth prevalence rate (total and by maternal age) of major congenital anomalies per 10000 live births was calculated. Of all 7451 live newborns suffering from congenital anomalies at birth during 2000-2010, there were 4927 cases of major congenital anomalies. The distribution of major congenital anomaly subgroups by gender was also analyzed. Major congenital anomalies were defined as lethal (if the defects cause stillbirth or infant death or pregnancies are terminated after a prenatal diagnosis) and severe (if the defects without medical intervention cause disability or death) defects together (17).

The data analysis was performed by SPSS for Windows (version 19). The chi-square test and linear regression were used for the data analysis. Odds ratios (OR) and 95\% confidence intervals (CI) were computed to determine associations between maternal age and likelihood of having a newborn with a congenital anomaly. This study was approved by the Ethics Committee of Riga Stradins University (January 21, 2011).

\section{Results}

Trends in Live Birth Prevalence Rate of Congenital Anomalies. There were 4927 newborns with major congenital anomalies diagnosed at birth during 2000-2010, representing $2.1 \%$ of all live births during 2000-2010. During the same period, the average live birth prevalence of major congenital anomalies was 211.40 per 10000 (95\% CI, 192.4-230.9). The prevalence rate decreased significantly from 204.8 per 10000 (95\% CI, 185.5-225.6) in 2000 to 191.2 per $10000(95 \%$ CI, 162.6-201.3) in 2010. With an average decrease of $5.2(\mathrm{y}=-5.2148 \mathrm{x}+243.17$; $R^{2}=0.5292$ ), the trend toward a decreasing prevalence by year was found to be significant $(P<0.01)$ (Fig. 1).

The most common anomalies (Table 1) in all the maternal age groups were congenital heart defects with a total live birth prevalence rate of 72.26 per 10000 live births (95\% CI, 32.0-72.3), followed by limb defects at a rate of 41.23 per 10000 (95\% CI, $31.8-41.2)$ and urinary system anomalies at a rate of 27.59 per 10000 (95\% CI, 26.0-29.7). The prevalence rate of limb defects decreased significantly $\left(\mathrm{y}=-1.0781 \mathrm{x}+12.207 ; R^{2}=0.8609 ; P<0.001\right)$.

Gender and Congenital Anomalies. The live birth prevalence rate of major congenital anomalies for boys was 229.6 per 10000 and for girls 192.33 per 10 000; the gender differences were statistically significant $(P<0.001)$.

There was a 2 -fold higher prevalence rate for boys than girls in relation to urinary system anomalies, i.e., 36.1 per 10000 (95\% CI, 32.7-39.6) for boys compared with 18.7 per 10000 (95\% CI, 16.3-21.4) for girls $(P<0.01)$. Boys also had an 8 -fold higher rate for genital congenital anomalies $(P<0.001)$ with

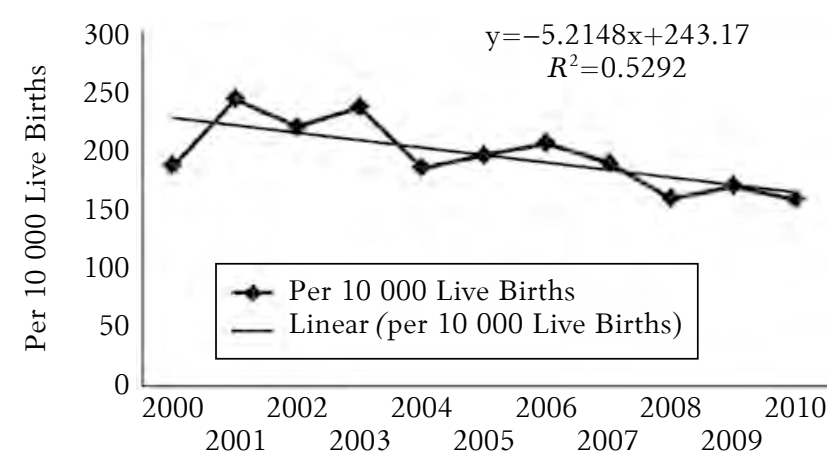

Fig. 1. The prevalence rate of major congenital anomalies per 10000 live births in Latvia (2000-2010) 
Table 1. Live Birth Prevalence Rates According to the Subgroups of Major Anomalies Registered in Medical Birth Register and Maternal Age in Latvia (2000-2010)

\begin{tabular}{|c|c|c|c|c|c|}
\hline \multirow{3}{*}{ EUROCAT Anomaly Subgroup } & \multirow{3}{*}{ ICD-10 } & \multicolumn{4}{|c|}{$\begin{array}{l}\text { Live Birth Prevalence per } \\
10000 \text { Births }\end{array}$} \\
\hline & & \multirow{2}{*}{ Total } & \multicolumn{3}{|c|}{ Maternal Age } \\
\hline & & & $\leqslant 19$ & $20-34$ & $\geqslant 35$ \\
\hline Nervous & Q00, Q01, Q02, Q03, Q04, Q05, Q06, Q07 & 9.23 & 7.81 & $9.00 *$ & $11.81^{*}$ \\
\hline Eye & Q100, Q104, Q106-Q107, Q11-Q15 & 0.51 & 0.49 & 0.49 & 0.74 \\
\hline Ear, face, and neck & Q16, Q178, Q183, Q188 & 1.29 & 0.98 & 1.35 & 1.11 \\
\hline Congenital heart defects & Q20-Q26 & 72.26 & 37.10 & $75.48^{*}$ & $76.78^{*}$ \\
\hline Respiratory & Q30-Q34 & 0.69 & 0.00 & 0.81 & 0.37 \\
\hline Orofacial clefts & Q35-Q37 & 11.33 & 10.74 & 11.11 & 13.29 \\
\hline Digestive system & Q38-Q39, Q402-Q409, Q41-Q45, Q790 & 9.78 & 3.91 & $9.92 *$ & $13.29^{*}$ \\
\hline Abdominal wall defects & Q792, Q793, Q795 & 4.98 & 5.37 & 5.07 & 4.06 \\
\hline Urinary & Q60-Q64, Q794 & 27.59 & 13.67 & $29.01 *$ & $28.42 *$ \\
\hline Genital & Q50-Q52, Q54-Q56 & 13.52 & 10.25 & 13.16 & $18.46^{*}$ \\
\hline Limb & $\begin{array}{l}\text { Q650-Q652, Q658-Q659, Q660, Q681-Q682, } \\
\text { Q688, Q69-Q74 }\end{array}$ & 41.23 & 18.55 & $43.29^{*}$ & $44.29^{*}$ \\
\hline Musculoskeletal system & $\begin{array}{l}\text { Q750-Q751, Q754-Q759, Q761-Q764, } \\
\text { Q766-Q769, Q77, Q78, Q796-Q799 }\end{array}$ & 1.41 & 1.46 & 1.35 & 1.85 \\
\hline Other anomalies/syndromes & Q27, Q28, Q80-Q85, Q89 & 10.08 & 0.49 & 0.54 & 0.74 \\
\hline Chromosomal & Q90-Q92, Q93, Q96-Q99 & 8.92 & 3.91 & 5.82 & $33.96^{*}$ \\
\hline $\begin{array}{l}\text { Total major congenital anomalies } \\
\text { subgroups }\end{array}$ & & 211.40 & 118.13 & $214.48^{*}$ & $260.96^{*}$ \\
\hline $\begin{array}{l}\text { Total congenital anomalies } \\
\text { (incl. minor anomalies, excluded } \\
\text { from EUROCAT subgroups) }\end{array}$ & Q00-Q99 & 319.71 & 176.22 & $330.50 *$ & $354.35^{*}$ \\
\hline
\end{tabular}

${ }^{*} P<0.05$ compared with mothers aged $\leqslant 19$ years.

a rate of 23.8 per $10000(95 \% \mathrm{CI}, 21.1-26.8)$ for boys and 2.7 per 10000 (95\% CI, 1.9-3.9) for girls. However, girls had a slightly higher prevalence rate of congenital heart defects and limb defects than boys; however, these differences were not statisti- cally significant. In the subgroups of other congenital anomalies, the prevalence rates were similar between both genders (Fig. 2.).

Maternal Age and Congenital Anomalies. The live birth prevalence rate of major congenital anomalies

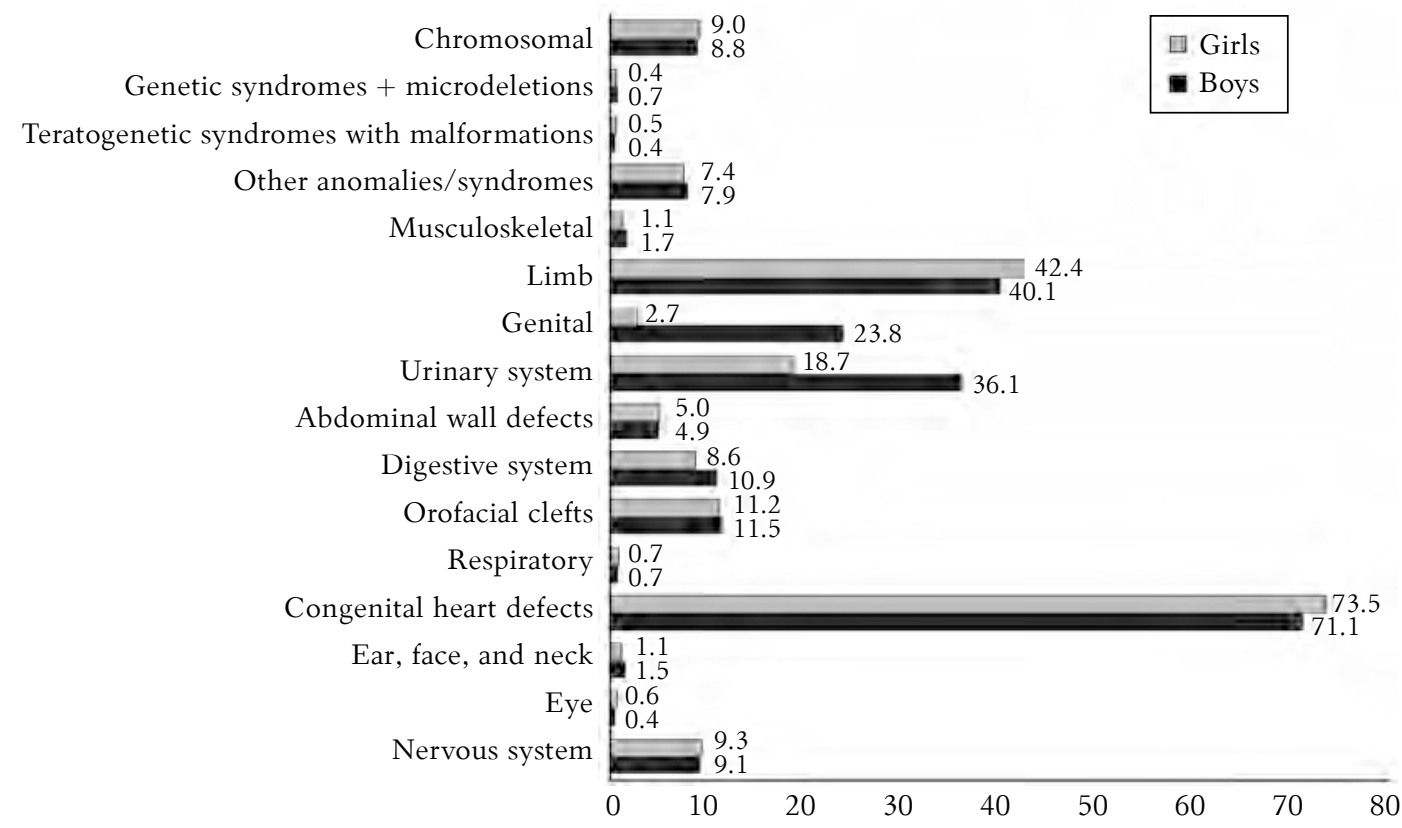

Fig. 2. The prevalence rate of major congenital anomalies per 10000 live births by gender in Latvia (2000-2010) 
Table 2. Percentage Distribution of Mothers Having Newborns With Major Congenital Anomalies Diagnosed at Birth by Characteristics of Mothers and Their Newborns and Maternal Age (2000-2010)

\begin{tabular}{|c|c|c|c|c|}
\hline \multirow{2}{*}{\multicolumn{2}{|c|}{ Characteristic }} & \multicolumn{3}{|c|}{ Maternal Age, Years } \\
\hline & & $\leqslant 19$ & $20-34$ & $\geqslant 35$ \\
\hline Marital status & Unmarried & 77.5 & $41.5^{*}$ & $38.5^{*}$ \\
\hline Antenatal care & Without care & 5.0 & 2.9 & $6.2 \dagger$ \\
\hline Gestational age & $22-36$ weeks & 10.3 & 7.8 & $12.0 \dagger$ \\
\hline Birth weight & $\leqslant 2499 \mathrm{~g}$ & 7.4 & 7.8 & $10.6 \dagger$ \\
\hline Delivery & Primipara & 90.5 & $56.0 *$ & $18.4^{*}$ \\
\hline History of maternal diseases & Yes & 39.0 & 34.8 & 36.2 \\
\hline Complications during pregnancy & Yes & 39.6 & 40.2 & $45.5 \dagger$ \\
\hline Complications during delivery & Yes & 35.2 & $47.3^{*}$ & $45.5^{*}$ \\
\hline History of medical abortions & Yes & 1.3 & 1.7 & $3.4^{*}$ \\
\hline
\end{tabular}

Values are percentage.

$* P<0.05$ compared with mothers aged $\leqslant 19$ years; $\dagger P<0.05$ compared with mothers aged $20-34$ years.

in newborns increased with maternal age: 118.1 per 10000 (95\% CI, 103.7-133.9) for mothers aged up to 19 years, 214.5 per 10000 (95\% CI, 195.5-235.0) for mothers aged $20-34$ years, and 261.0 per 10000 (95\% CI, 194.0-234.2) for mothers aged 35 years and more. The total prevalence rates significantly increased in the maternal age groups of 20-34 years old and 35 and older when compared with mothers aged up to 19 years $(P<0.001)$ (Table 2$)$.

The mean age of all mothers having newborns with major congenital anomalies was 27.82 years (SD, 6.0). The mean maternal age differed by the diagnosis of congenital anomaly subgroups. Mothers having newborns with eye anomalies and abdominal wall defects were slightly younger (26.63 years [SD, 6.65] and 26.01 years [SD, 5.77], respectively). Significant differences in the mean age of mothers having newborns with congenital anomalies by congenital anomalies subgroups were found: 33.36 (SD, 5.29) with a difference of 5.54 years $(95 \% \mathrm{CI}$, $-5.76 ;-5.32)$ for teratogenic syndromes and 32.49 (SD, 7.43) with a difference of 4.67 years $(95 \% \mathrm{CI}$, $-4.93 ;-4.40)$ for chromosomal anomalies.

The live birth prevalence rates were significantly higher in older maternal age groups for nervous, cardiac, digestive and urinary system, limb defects, and genital and chromosomal anomalies.

Relationships Between Maternal Age and Congenital Anomalies. The study results showed an age-related risk of abdominal wall defects, orofacial clefts, and chromosomal anomalies. Mothers younger than 20 years were more likely to have newborns with orofacial clefts (OR, 1.8; 95\% CI 1.2-2.3; $P<0.01$ ), abdominal wall defects (OR, 1.97; 95\% CI 1.2-3.5; $P<0.05$ ), and chromosomal abnormalities (OR, 2.4; 95\% CI 1.2-5.2; $P<0.05)$ compared with mothers aged 20-34 years. Meanwhile, older mothers (35 years and more) had a 3-fold greater likelihood of having a newborn with abdominal wall defects (OR, 3.0; 95\% CI, 1.2-7.6; $P<0.01)$ in comparison with mothers younger than 20 years. Mothers aged 35 years and more were 5 and 2 times more likely to have a newborn with chromosomal anomalies other than congenital anomalies than 20- to 34-year-old mothers (OR, 5.4; 95\% CI, 4.0-7.2; $P<0.001)$ and mothers younger than 20 years (OR, 2.2; 95\% CI, $1.1-5.1 ; P<0.05)$.

Differences in Characteristics of Mothers by Age Groups. There were differences in the percentage distribution of mothers having newborns with major congenital anomalies by maternal characteristics and age groups (Table 2). There were differences between the maternal age groups by parity, where the largest proportion of primiparas was found among mothers aged 19 years and less compared with 20- to 34-year-old mothers $\left(\chi^{2}=111.37 ; P<0.001\right)$ and those aged 35 years and more $\left(\chi^{2}=403.18 ; P<0.001\right)$. Mothers aged $20-34$ years $\left(\chi^{2}=10.16 ; P<0.001\right)$ and aged 35 years and more $\left(\chi^{2}=6.06 ; P<0.01\right)$ had complications during delivery more frequently than those aged up to 19 years. A significantly higher proportion of preterm births (from 22 to 36 gestational week) $\left(\chi^{2}=14.11\right.$; $P<0.001)$, low birth weight of newborns $(\leqslant 2499 \mathrm{~g})$ $\left(\chi^{2}=6.18 ; P<0.01\right)$, and complications during pregnancy $\left(\chi^{2}=5.78 ; P<0.05\right)$ were among mothers aged 35 years and more in comparison with mothers aged 20-34 years.

\section{Discussion}

Congenital anomalies are one of the major causes of pregnancy loss, stillbirth, neonatal death, and physical defects and disabilities around the world (1-3). The analysis of the data from the Medical Birth Register of Latvia showed that the live birth prevalence rate of major congenital anomalies in newborns increased with the maternal age. These findings are consistent with the results of other published studies (7, 10-15).

The mean maternal age has increased in Latvia in the past few decades $(4,6)$. In the United States, the number of first births per 1000 women aged 35 to 39 years increased by 36\% between 1991 and 2001 (7). Even though the average maternal 
age increased, the prevalence of major congenital anomalies decreased between 2000 and 2010. A decreasing tendency in the total prevalence rate of congenital anomalies, also observed in the WHO and EUROCAT data, is mainly explained by better antenatal care and improved management of known risk factors, such as chronic maternal health conditions (e.g., diabetes), and the reduction of health risk behaviors (e.g., smoking) (2, 5, 18). However, it should be mentioned that the EUROCAT total prevalence rates of congenital anomalies included the cases of live births, stillbirths, and terminations of pregnancy due to fetal anomalies (2).

The total and live birth prevalence of congenital anomalies could be higher in Latvia if cases of congenital anomalies detected in newborns aged up to 1 year as well as the termination of pregnancy due to congenital anomalies were included. There is no information on cases diagnosed during the postneonatal period in the Medical Birth Register.

The aim of this study was to analyze only the live birth prevalence rate of congenital anomalies at birth. There is no comprehensive statistical information about the terminations of pregnancy due to congenital anomalies. In this regard, additional studies are needed in Latvia to determine the prevalence rates of the terminations of pregnancy due to different reasons, including birth defects.

The data from the Medical Birth Register of Latvia revealed that mothers who delivered babies with major congenital anomalies had an average age of 27.82 years, which was significantly greater (by more than 4 years) for mothers who had newborns with chromosomal anomalies (32.49 years). It corresponds to the results of other publications. The advancing maternal age increases the risk of certain chromosomal abnormalities, especially Down syndrome $(1,2,12-15)$. According to the EUROCAT data, the live birth prevalence rate of Down syndrome for the 2000-2004 period was 9.65 per 10000 births (2). In Latvia, the live birth prevalence rates of chromosomal anomalies and Down syndrome were slightly lower, i.e., 8.92 and 7.98 per 10 000, respectively. In England, the mean age of mothers of live born children with Down syndrome increased from 30.6 years in 1989/1990 to 34.4 years in 2007/2008, while the mean age of mothers of antenatally diagnosed cases decreased (15). In Latvia, the mean age of mothers of newborns with Down syndrome remained the same: 31.1 (SD, 8.3 ) in 2000 and 31.5 (SD, 6.4) in 2010, with the mean age of 33.0 years $(\mathrm{SD}, 7.4)$ during this period (2000-2010).

Some publications have indicated that women aged 25 years and more at delivery had a significantly greater risk of having fetuses with nonchromosomal anomalies when compared with women aged between 20 and 24 years $(10,11)$. Very young mothers have an increased risk of adverse pregnancy outcomes. Studies have noted that teenage mothers more likely than older mothers belong to a lower socioeconomic group, are less educated, unmarried, and are less likely to have early prenatal care (9). Multivitamin use is also lowest among pregnant women younger than 20 years (8). Studies have shown that a higher proportion of mothers in Latvia did not receive antenatal care. This was observed in both the groups of women younger than 20 years $(5.0 \%)$ and aged 35 and more $(6.2 \%)$. This could be explained by a larger proportion of unplanned pregnancies in those groups.

The importance of antenatal care as a predictor of a favorable outcome of childbirth, including a reduced risk of low birth weight, premature births, and infant mortality, has been widely described in the literature (19-24). These results indicate that delayed antenatal care is a risk factor for the late neonatal diagnosis of congenital abnormalities. This interferes in some cases with an early termination of pregnancy due to medical reasons. An early detection of birth defects can ensure adequate maternity assistance in tertiary hospital maternity units and reduce health complications and premature death of a newborn.

There were associations between inadequate antenatal care and preterm deliveries, which were also more frequent in women younger than 19 years or older than 35 years. In fact, $10.3 \%$ of pregnancies among mothers aged up to 19 years and $12.0 \%$ among mothers aged 20 to 34 years resulted in preterm deliveries. The distribution of mothers by parity indicated that $90.5 \%$ of mothers younger than 20 years were primiparas compared with $56.0 \%$ of mothers aged $20-34$ years and $18.4 \%$ of mothers aged 35 years and more. The data are similar with the EUROCAT data, where primiparas made up $80 \%$ of mothers aged up to 20 years, $55 \%$ of mothers aged 20 to 24 years, and $46 \%$ of mothers aged 25 to 29 years (23).

Congenital heart defects were the anomalies with the highest live birth prevalence rate during our study period (2000-2010). However, the prevalence rate in Latvia was quite similar to the average prevalence rate reported for Europe during 2000-2005 (7.2 per 1000 births). Congenital heart defects account for nearly one-third of all major congenital anomalies diagnosed either prenatally or in infancy in Europe (23). In this study period (2000-2010), the live birth prevalence rate of congenital heart defects was 72.26 per 10000 . Vital statistical data show that family practitioners detected an average of $0.3 \%-0.5 \%$ (2007-2010) of congenital heart diseases in babies aged up to 1 year of all live births (24). In this study, the most common congenital heart 
defects detected at birth were congenital malformations of cardiac septa (Q21; 50\% of all heart defects, $\mathrm{n}=838)$. Persistent ductus arteriosus (Q21.1, PDA) and foramen ovale apertum (Q25.0) accounted for $6.5 \%(n=110)$ and $10.9 \%(n=183)$ of all congenital heart defects (Q20-Q26), respectively. In literature, the reported incidence of PDA varies from 5\% to $10 \%$ of all congenital heart diseases (25). Premature newborns made up $8.5 \%(n=419)$ of all the study population, and premature live newborns with congenital heart defects accounted for $2.3 \%(n=113)$ of all newborns with major congenital anomalies or $6.7 \%$ of all newborns with congenital heart defects. The proportion of premature newborns with PDA $(n=7)$ and foramen ovale $(n=8)$ was $4.4 \%$ of all newborns with anomalies in each group at birth. Other study reported that every third preterm infant with a very low birth weight of 501 to $1500 \mathrm{~g}$ could be expected to have a persistent PDA (26).

In the present study, mothers younger than 20 years had a significantly increased risk of having a newborn with abdominal wall defects (OR, 3.0) when compared with mothers aged 35 years and more. These findings are consistent with the data of other studies. The data from the US have shown that the OR of gastroschisis was higher in newborns of mothers younger than 15 years and aged 16-19 years $(\mathrm{OR}=1.21$ and $\mathrm{OR}=1.68$, respectively) when compared with the 20-24-year age group (10). The EUROCAT data show that the highest prevalence of all nonchromosomal anomalies was observed in babies of mothers younger than 20 years (11).

The study from the United States estimated that different complications of pregnancy increased steadily with women's age; one example is hypertensive complications, which are twice as likely to occur in women aged 40 years or more when compared with younger women (8). Our study findings were similar: significantly higher proportions of preterm births, newborns with low birth weight, and complications during pregnancy were found in mothers aged 35 years and more when compared with the 20-34-year age group.

Clinical and public health interventions are needed to reduce risk factors, with special attention focused on younger mothers' lifestyle factors and health education as well as other factors. For mothers of all ages, family planning, antenatal care, and improvements in examinations to detect congenital anomalies (initial screenings) are also very important.

One of the limitations to this study is that the MBR is difficult to be linked with other databases and registers in Latvia because the information in the MBR is based on the mother's personal code; meanwhile, other databases are based on the infant's/child's personal code. Each registry is located within a different information system, and each of them uses a different method to gather the data. Therefore, it is difficult to compare and analyze the data in a unified way. During the last years, many efforts have been made to set up and improve the process of data linkage in Latvia. Since 2010, the MBR is a part of the Register of Patients Suffering from Certain Diseases, which includes separate different registers (such as Diabetes Register, Register of Patients Suffering From Mental Diseases and Alcohol Abuse, Trauma Register, etc.). All these registers serve as separate units, but technically they are linked together into one data system. The process of online filling of medical documentation for the MBR and cooperation with hospitals and perinatal centers in order to include and validate congenital anomaly diagnoses of newborns after their discharge from the maternity unit is expected to start in 2013.

The MBR is based on the information provided by medical documentation (MBR cards), issued to a newborn by maternity units, and on the cases of congenital anomalies diagnosed during the stay in a maternity unit. Birth defects diagnosed later are not included in the MBR. The observation period for the detection of congenital anomalies usually depends on the length of hospital stay after delivery.

Nevertheless, the MBR contains the information essential for epidemiological studies and surveys on perinatal health, including the data on all newborns and their characteristics. The benefit of research would increase if the data from the MBR were combined with the data from other sources in the future.

To date, there are no such large epidemiological studies done on major congenital anomalies in Latvia. This type of data analysis provides better understanding of the problem of congenital anomalies from the perspective of the population and allows the detection of risk groups and risk factors during pregnancy, at birth, and later during neonatal period. All the discovered risks can be used as the indicators of prevention and early detection of congenital anomalies.

These findings also underscore the importance of further research into the analysis of the associations between the maternal age and occurrence of congenital anomalies.

\section{Conclusions}

The data on congenital anomalies from the Latvian Medical Birth Register have not been widely used before. However, this study shows that the MBR data may be useful for epidemiological studies on congenital anomalies in Latvia. All the results are consistent with similar results from the studies in other countries. The results of this 11-year retrospective study showed a decreasing trend of the live birth prevalence of major congenital anomalies 
in Latvia. However, the prevalence rates of the majority of congenital anomalies increase with maternal age. Significantly higher proportions of preterm births, newborns with low birth weight, and complications during pregnancy were documented in the older maternal age groups.

\section{Acknowledgments}

This work was supported by the European So-

\section{References}

1. Christianson A, Howson CP, Modell B. March of dimes: global report on birth defect. New York; 2006. p. 2-10; 14; 19. Available from: URL: http://marchofdimes.com/downloads/Birth Defects Report-PF.pdf

2. Special report: the status of health in the European Union: congenital malformations. EUROCAT Central Registry. June 2009:4. Available from: URL: http://www.eurocat-network.eu/content/Special-Report-Con-Malfs.pdf

3. Birth defects. Report by Secretariat. World Health Organization. Sixty-third World Health Assembly. Provisional agenda item 11.7. A63/10, 1 April 2010. p. 1-7.

4. Latvijas veselïbas aprūpes statistikas gadagrāmata 2010. Veselības ekonomikas centrs. (Yearbook of health care statistics in Latvia 2010. The Centre of Health Economics.) Riga; 2011. p. 30, 183.

5. European health for all databases (HFA-DB). World Health Organization Regional Office for Europe. Updated: January 2011.

6. The Central Statistical Bureau of Latvia. Statistics database. Available from: URL: http://www.csb.gov.lv/en/dati/statistics-database-30501.html

7. Heffner LJ. Advanced maternal age - how old is too old? New Engl J Med 2004;351(19):1927-8.

8. Society for reproductive, endocrinology and infertility. Available from: URL: http://www.ivf1.com/age-birth-defects/

9. Fraser AM, Brockert JE, Ward RH. Association of young maternal age with adverse reproductive outcomes. New Engl J Med 1995;332(17):1113-7.

10. Hollier LM, Leveno KJ, Kelly MA, MCIntire DD, Cunningham FG. Maternal age and malformations in singleton birth. Obstet Gynecol 2000;96(5):701-6.

11. Loane M, Dolk H, Morris JK; EUROCAT Working Group. Maternal age-specific risk of non-chromosomal anomalies. BJOG 2009;116:1111-9.

12. Pasupathy D, Wood AM, Pell JP, Fleming M, Smith GC. Advanced maternal age and the risk of perinatal death due to intrapartum anoxia at term. J Epidemiol Community Health 2011;65:241-5.

13. Hook EB, Lindsjo A. Down Syndrome in live births by single year maternal age interval in a Swedish study: Compari- cial Fund (ESF) national program "Support for PhD Programs and Postdoctoral Research" project "Support for Doctoral and Postdoctoral Research in Medical Science" and the ESF project "Support for Doctoral Study Program and Research Degrees in Riga Stradins University” grant.

\section{Statement of Conflict of Interest}

The authors state no conflict of interest.

son with results from a New York study. Am J Hum Genet 1978;30(19):19-27.

14. Hook EB. Rates of chromosome abnormalities at different maternal ages. Obstet Gynecol 1981;58(3):282-5.

15. Morris JK, Alberman E. Trends in Down's syndrome live birth and antenatal diagnoses in England and Wales from 1989 to 2008: analysis of data from the National Down Syndrome Cytogenetic Register. BMI 2009;339:1-5.

16. Coding of EUROCAT subgroups of congenital anomalies. Available from: URL: http://www.eurocat-network.eu/ aboutus/datacollection/guidelinesforregistration/malformationcodingguides

17. Czeizel AE. Birth defects are preventable. Int J Med Sci 2005;2:91-2.

18. EUROCAT Central Registry. EUROCAT statistical monitoring report - 2009. Available from: URL: $\underline{\text { http://www.eu }}$ rocat-network.eu/content/Stat-Mon-Report-2009-Combined.pdf

19. Malcoe LH, Shaw GM, Edward J, Herman AA. The effect of congenital anomalies on mortality risk in white and black infants. Am J Public Health 1999;89(6):887-92.

20. Yoon PW, Rasmussen SA, Lynberg MC, Moore CA, Anderka M, Carmichael SL, et al. The National Birth Defects Prevention Study. Public Health Rep 2001;116(1):32-40.

21. Costa CMS, Gama SGN, Leal MC. Congenital malformations in Rio de Janeiro, Brazil: prevalence and associated factors. Cad Saude Publica 2006;22(11):2423-31.

22. Tootoonchi P. Easily identifiable congenital anomalies: prevalence and risk factors. Acta Med Iran 2003;41(1):15-9.

23. Dolk H, Loane M, Garne E; European Surveillance of Congenital Anomalies (EUROCAT) Working Group. Congenital heart defects in Europe: prevalence and perinatal mortality, 2000 to 2005. Circulation 2011;123:841-9.

24. Centre for Disease Prevention and Control of Latvia. Children health. Available from: URL: http://www.spkc.gov.lv/ veselibas-aprupes-statistika/

25. Schneider DJ, Moore JW. Patent ductus arteriosus. Circulation 2006;114:1873-82.

26. Hamrick EG, Hansmann G. Patent ductus arteriosus of the preterm infant. Pediatrics 2010;125(5):1020-30. 